https://doi.org/10.33871/23594381.2020.18.1.98-120

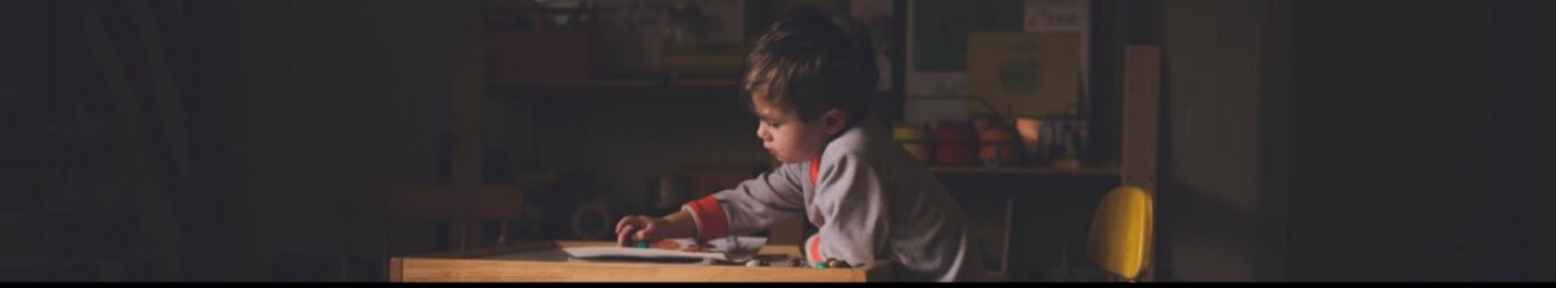

Ensino \& Pesquisa magazine is an interdisciplinary journal of the State University of Paraná, Center for Humanities and Education. Its objective is to publish scientific articles focused on undergraduate and teacher education. (Preprints Policy-AUTHOREA Plataform) ISSN: 2359-4381

\title{
Contribuições da metodologia da problematização para o desenvolvimento profissional docente em educação para a sexualidade
}

Luciana Uchôa Barbosa, Mestre pelo Programa de Pós Graduação Educação em Ciências: Química da Vida e Saúde - UFRGS, Doutoranda do Programa de Pós Graduação Educação em Ciências: Química da Vida e Saúde - UFRGS, luciana.uchoa@belojardim.ifpe.edu.br

Jaqueline Copetti, Mestre em Educação Física (UFPEL), Doutora em Educação em Ciências: Química da Vida e Saúde (UFSM), jaqueline.copetti@gmail.com

Vanderlei Folmer, Doutor em Ciências Biológicas (UFSM), Pós doutorado em Bioquímica Toxicológica (Universidade de Lisboa-Portugal) e Docente no Programa de Pós-Graduação Educação em Ciências: Química da Vida e Saúde (Unipampa), vanderleifolmer@unipampa.edu.br

Resumo: O presente estudo tem como objetivo identificar as possíveis contribuições da metodologia da problematização com o arco de Maguerez no desenvolvimento profissional docente em educação para a sexualidade. Para isso, foi realizada uma pesquisa exploratória e descritiva com abordagem qualitativa. Participaram da pesquisa docentes que atuavam no ensino fundamental II ( $6^{\circ}$ ao $9^{\circ}$ ano) de uma escola no interior de Pernambuco. A pesquisa foi realizada em três fases. Na primeira fase foi aplicado um questionário constituído por questões abertas. Posteriormente, foi realizado o desenvolvimento profissional docente tendo como temática a educação para a sexualidade. Essa atividade foi desenvolvida utilizando a metodologia da problematização com o arco de Maguerez. A última fase consistiu de outro questionário pós DPD, para identificar as possíveis contribuições da metodologia da problematização para um novo fazer pedagógico abordando a educação para a sexualidade no contexto escolar. Os resultados apontaram que a utilização da metodologia da problematização com o arco é uma estratégia que possibilita inúmeras contribuições para a prática docente. Pois permite ao educador ser o protagonista na construção do seu próprio conhecimento. A metodologia também favorece a coletividade desde o levantamento de problemas até a construção de soluções para a transformação da realidade. Também foi possível constatar que a MP com o arco de Maguerez, proporciona segurança e autonomia ao professor para a abordar o tema sexualidade em sala de aula. Revelou-se ainda ser eficaz na integração entre os familiares e a escola para discussão e reflexão acerca do tema em ambos os contextos. Diante do exposto, fica a proposta de utilizar a MP com o arco de Maguerez como estratégia para o desenvolvimento profissional docente em educação para a sexualidade. Considerando que trata -se de um tema pertinente, sugere-se que novas pesquisas sejam realizadas envolvendo os adultos de referência (pais, professores e profissionais de saúde).

Palavras - chave: Formação docente, Educação sexual, Arco de Maguerez. 
Contributions of the problematization methodology to the teacher professional development in sexuality education

Abstract: The present study aims to identify the possible contributions of the problematization methodology with the Maguerez arc in the teacher professional development in sexuality education. For this, an exploratory and descriptive research with qualitative approach was performed. Teachers who worked in elementary school II (6th to 9th grade) of a school in the interior of Pernambuco participated in the research. He research was conducted in three phases. In the first phase a questionnaire consisting of open questions was applied. Subsequently, the teacher professional development was carried out with the theme of sexuality education. This activity was developed using the methodology of problematization with the Maguerez arc. The last phase consisted of another post DPD questionnaire to identify the possible contributions of the problematization methodology to a new pedagogical approach to sexuality education in the school context. The results pointed out that the use of the arc problematization methodology is a strategy that allows countless contributions to the teaching practice. For it allows the educator to be the protagonist in the construction of his own knowledge. The methodology also favors the collectivity from the raising of problems to the construction of solutions for the transformation of reality. It was also found that MP with the Maguerez bow provides security and autonomy to the teacher to address the issue of sexuality in the classroom. It was also shown to be effective in integrating family and school for discussion and reflection on the theme in both contexts. Given the above, it is proposed to use MP with the Maguerez arch as a strategy for the professional development of teaching in sexuality education. Considering that this is a pertinent theme, it is suggested that further research be conducted involving reference adults (parents, teachers and health professionals).

Keywords: Teacher training, Sexual education, Maguerez Arch.

Submissão: 2019-11-23. Aprovação: 2020-03-11. Publicação: 2020-04-17

\section{Introdução}

Embora as questões sobre sexualidade estejam presentes no cotidiano da escola, este tema ainda encontra barreiras como o tabu, medo e mitos. Estes obstáculos têm como um dos motivos a falta de conhecimento por parte dos profissionais da educação. Mediante tal contexto, torna-se necessário que o professor tenha acesso a atividade relacionada ao desenvolvimento profissional docente, que aborde a temática sexualidade. Nesta direção, Santos (2018) explica que o desenvolvimento profissional docente contribui para que o professor modifique sua postura e práticas pedagógicas, e atenda às demandas da sexualidade dos adolescentes escolares.

No Brasil, estudos reconhecem que os educadores têm dificuldade em trabalhar a educação sexual com seus alunos. Essas dificuldades são decorrentes da falta de preparo e pouco investimento em formação inicial e continuada. (FURLANETTO et al., 2018; SANTOS, 2018; SANTOS E SANTOS,2019). Corroborando com essa inferência Silva e Nobre (2017) asseveram que conteúdos relacionados a educação sexual devem fazer parte dos cursos de formação inicial e continuada docente. Visando garantir aos alunos conhecimentos suficientes para o cuidado com a sua saúde sexual e do coletivo. 
Cabe ressaltar que nessa pesquisa optou-se pela denominação desenvolvimento profissional docente, pelo fato de que este termo melhor se adapta a proposta da pesquisa, pois de acordo com Marcelo (2009):

\begin{abstract}
Entende-se o desenvolvimento profissional dos professores como um processo individual e colectivo que se deve concretizar no local de trabalho do docente: a escola; e que contribui para o desenvolvimento das suas competências profissionais, através de experiências de índole diferente, tanto formais como informais (MARCELO, 2009, p.7).
\end{abstract}

Outra justificativa pela escolha do termo baseia-se na explicação de Lacerda e Melo (2017) que o desenvolvimento profissional docente não se restringe a um modelo tradicional de transmissão de conhecimento. Mas, possibilita a construção do conhecimento, buscando identificar e compreender os problemas que ocorrem durante o processo de ensino-aprendizagem, para posteriormente encontrar as soluções dos problemas.

Ainda, as autoras ressaltam que o processo de formação docente deve ser planejado a partir das necessidades da realidade escolar e ter como propósito o desenvolvimento das habilidades docente para contribuir na transformação dessa realidade. Diante do exposto, buscou - se realizar um estudo com o objetivo de identificar as possíveis contribuições da metodologia da problematização com o arco de Maguerez para o desenvolvimento profissional docente em educação para a sexualidade.

\title{
A importância do desenvolvimento profissional docente em educação para a sexualidade
}

Poucas pesquisas têm sido realizadas acerca do DPD em educação para sexualidade, apesar do aumento de estudos relacionados ao no contexto escolar. "Do ponto de vista educacional estudos sobre o tema em questão é imprescindível para obter informações que possam auxiliar no planejamento de ações educativas eficientes que favoreçam o desenvolvimento das crianças" (GONÇALVES, PAES E FAVORITO, 2015). Logo, o DPD é nitidamente um componente importante para a eficácia da educação para a sexualidade nas escolas e é uma oportunidade para construir uma base sólida para a implementação deste trabalho.

Carman et al. (2011) também apontam que o desenvolvimento profissional docente pode ajudar a reduzir barreiras e desafios na implementação da educação para sexualidade

Ensino \& Pesquisa, União da Vitória, v. 18, $n^{\circ} 1$, p. 98-120, jan./abr., 2020. 
no contexto escolar e melhorar a qualidade do ensino, a partir do momento em que os professores passam a se sentirem mais seguros diante do tema. Ainda, segundo os autores, o tema sexualidade na adolescência não pode deixar de ser implementado na escola, ou não avance por falta de formação do profissional docente. Nesse sentindo, Amaral et al. (2015) consideram a escola como um local privilegiado para o desenvolvimento profissional docente em educação sexual, pois:

Trata-se de um espaço em que as relações de poder historicamente construídas permeiam as relações da comunidade no âmbito escolar, uma vez que, nessa instituição são transmitidos os padrões de sociabilidade, os valores e a moral, onde há o condicionamento das concepções de sexualidade e gênero (AMARAL,2015, P.47)

Porém, pesquisa realizada por Barbosa, Viçosa e Folmer (2019) aponta que no Brasil não existe uma política pública que regulamenta a inserção do tema educação para sexualidade nos currículos dos cursos das licenciaturas. Assim como a obrigatoriedade do ensino sobre sexualidade nas escolas, o que favorece para o negligenciamento do tema no contexto escolar. Diferente da realidade do Brasil, países da Europa tem dentro do curriculo escolar a disciplina de educação sexual há mais de meio século. Em Portugal foi criada a Lei $\mathrm{n}^{\circ}$. 60/2009, que estabelece o regime de aplicação da educação sexual em meio escolar, no ensino básico e no ensino secundário da rede pública e privada. Bem como é garantido pela referida Lei o desenvolvimento profissional docente para a construção de habilidades em educação sexual.

\begin{abstract}
Aos professores-coordenadores de educação para a saúde e educação sexual, aos professores responsáveis em cada turma pela educação para a saúde e educação sexual e aos professores que integrem as equipes interdisciplinares de educação para a saúde e educação sexual, é garantida, pelo Ministério da Educação, a formação necessária ao exercício dessas funções (a Lei nº. 60/2009).
\end{abstract}

De acordo com a European Expert Group on Sexuality Education (2015) estudos realizados em vários países europeus, apontam que após a implementação de temas relacionados a sexualidade nas escolas, houve uma redução nos indices de gravidez e aborto na adolescência e das Doenças Sexualmente Transmissíveis. No entanto, para o trabalho de educaão para sexualidade tenha êxito, é fundamental que os professores estejam preparados para tal abordagem. Pois, Pound, Langford e Campbell (2016) destacam que a educação sexual ministrada por professores com pouco ou nenhum preparo pode reverberar negativamente na sexualidade dos adolescentes e adultos.

Ensino \& Pesquisa, União da Vitória, v. 18, $n^{\circ}$ 1, p. 98-120, jan./abr., 2020. 
Nesta mesma perspectiva, Imbernón (2010) ressalta que o desenvolvimento profissional docente deve ir além de um momento de reciclagem. Mas, uma oportunidade para a investigação científica que possibilite a reflexão, imaginação e transformação. Para o autor, é fundamental que o professor seja o protagonista na construção de novos conhecimentos, e com isso possa aproximar-se da sua prática educativa com mais autonomia e novas perspectivas.

\section{A metodologia da problematização com o Arco de Maguerez e sua contribuição como estratégia para uma ação transformadora da realidade}

A metodologia da problematização dá sua contribuição à educação ao possibilitar a aplicação à realidade. Pois, desencadeia uma transformação do real, acentuando o caráter pedagógico (BERBEL, 1998). Também é descrita por Peres et al. (2018) como uma metodologia que contribui para o desenvolvimento de profissionais críticos e reflexivos, com autonomia para transformar a realidade. Essa possibilidade pode ser realizada por meio da utilização do método do Arco de Maguerez. A qual foi escolhida para a realização desta pesquisa.

O Arco de Maguerez tem sido proposto como metodologia de ensino, de estudo e de trabalho em vários contextos. Pode ser utilizado em situações em que os temas estejam relacionados com a vida em sociedade e constitui um rico caminho para estimular o desenvolvimento de diversos saberes pelos seus participantes (ESPERIDIÃO et al, 2017, p.826).

A figura a seguir, permite visualizar as diferentes etapas da proposta de Maguerez:

Figura 1. Representação do Arco de Maguerez

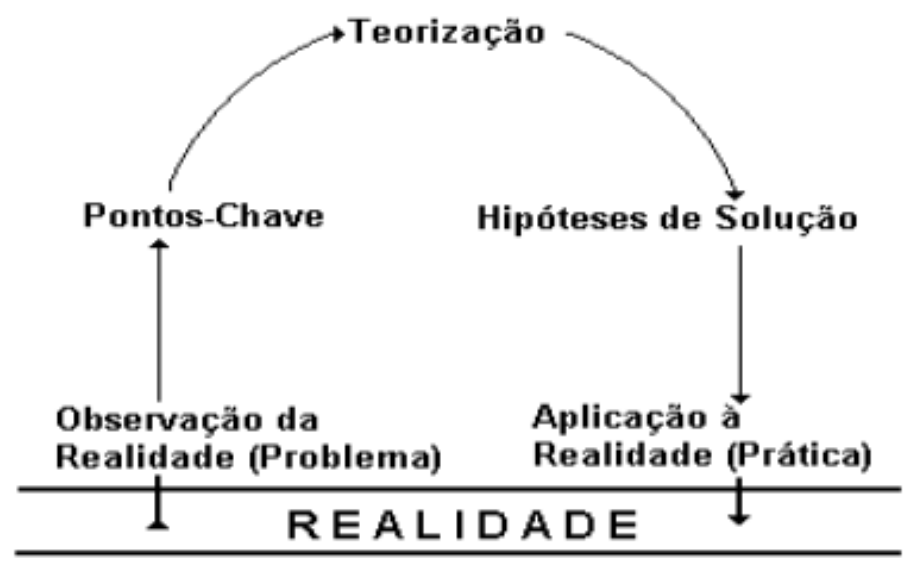

Fonte: Bordenave \& Pereira (1989).

Ensino \& Pesquisa, União da Vitória, v. 18, nº 1, p. 98-120, jan./abr., 2020. 
Como observado na figura 1, o processo de desenvolvimento do Arco de Maguerez segue por meio de cinco etapas: a observação da realidade e a identificação do problema, os pontos-chave, a teorização, as hipóteses de solução e a aplicação à realidade. Villardi et.al. (2015) explicam que este método traz como ponto de partida o olhar atento para a realidade. E ao término a retomada da realidade para transformá-la em situação melhor.

\section{Contexto da pesquisa e procedimentos metodológicos}

Trata-se de um estudo exploratório e descritivo, ancorado na abordagem qualitativa. O estudo foi realizado no Centro de Excelência Municipal - CEM, localizado no interior de Pernambuco. Os participantes da pesquisa foram professores de diversas áreas do ensino fundamental II ( $6^{\circ}$ ao $9^{\circ}$ ano).

A pesquisa foi desenvolvida em três fases, na primeira fase foi aplicado um questionário estruturado, autoaplicável, constituído por questões abertas no intuito de subsidiar o desenvolvimento profissional docente. A fase seguinte consistiu no desenvolvimento profissional docente utilizando a metodologia da problematização com o Arco de Maguerez. Tendo como temática a educação para a sexualidade. Essa proposta teve como escopo estimular discussões e reflexões acerca dos principais problemas na prática da educação sexual. Bem como, a concepção de sexualidade e apreensão de novos conhecimentos para a prática da educação sexual na escola. A terceira fase consistiu de outro questionário pós DPD, para identificar as possíveis contribuições da metodologia da problematização. A coleta de dados também foi realizada a partir da observação dos participantes e os registros do diário de campo.

Esta pesquisa foi submetida ao Comitê de Ética em Pesquisa e aprovada por meio do Certificado de Apresentação para Apreciação Ética (CAAE) nº 80815917.3.0000.5189 e Parecer de aprovação: 442.434 (15/12/2017). Após a aprovação pelo Comitê de Ética em Pesquisa, realizou-se o encontro com os professores para esclarecimentos sobre os objetivos da pesquisa e em seguida a assinatura do Termo de Consentimento Livre e Esclarecido. Sendo garantido o sigilo das informações por parte dos pesquisadores.

Os dados coletados foram organizados em categorias temáticas, desenvolvidas com base na Análise de Conteúdo. Considerando as seguintes etapas propostas por Bardin (2011): 1) Pré-análise, que compreende a leitura exaustiva, 2) exploração do material, que

Ensino \& Pesquisa, União da Vitória, v. 18, nº 1, p. 98-120, jan./abr., 2020. 
consiste na organização dos dados em categorias e 3) tratamento dos resultados, inferência e interpretação, em que as informações foram analisadas e emergiram interpretações inferenciais, críticas e reflexões.

\section{Resultados e discussão}

Para o início do desenvolvimento profissional docente, foi realizado pela pesquisadora, uma breve apresentação sobre a metodologia da problematização com o Arco de Maguerez, e em seguida, foi solicitado que os participantes formassem grupos, de acordo com o número de docentes presentes, que foram nomeados de G1 a G4. Na sequência serão apresentados os resultados de acordo com as etapas do arco de Maguerez, para melhor ilustrar o desenvolvimento de cada uma delas ao longo do processo de desenvolvimento profissional docente.

\section{$1^{\text {a }}$ Etapa - Observação da Realidade}

$\mathrm{Na}$ etapa da observação da realidade foi solicitado que os docentes realizassem uma reflexão coletiva acerca das inquietações e dificuldades frente a educação sexual na escola. Em seguida, cada grupo apresentou os problemas elencados para o grande grupo. Cabe ressaltar que esse momento foi oportuno e produtivo. Pois, os docentes socializaram suas experiências em relação à educação para a sexualidade.

Também foi possível perceber, por meio da fala dos professores, as principais dificuldades e desafios. Como também, reconhecer e refletir quanto a posturas, valores e conceitos atribuídos à temática. De acordo com Berbel, (1998).

Tal observação permitirá aos alunos identificar dificuldades, carências, discrepâncias, de várias ordens, que serão transformadas em problemas, ou seja, serão problematizadas. Poderá ser eleito um desses problemas para todo o grupo estudar ou então vários deles, distribuídos um para cada pequeno grupo (BERBEL, 1998, p.142).

Enquanto cada grupo realizava sua apresentação, fez-se o registro de cada fala dos professores através do diário de campo. Assim como, foi solicitado que no final cada grupo entregasse suas anotações. De acordo com os problemas elencados pelos professores, percebe-se que trabalhar a educação para a sexualidade na escola não é tarefa simples por diversos fatores, sendo a lacuna formativa relacionada ao tema um dos principais impeditivos. Os depoimentos que seguem vêm corroborar com este entendimento:

"Falta de capacitação dos professores sobre sexualidade" (Grupo3).

"Falta de uma formação continuada para professores, específico na área de educação sexual" (Grupo 2 e 4).

Ensino \& Pesquisa, União da Vitória, v. 18, $n^{\circ}$ 1, p. 98-120, jan./abr., 2020. 
Segundo estudo realizado por Anastácio (2018) professores que recebem formação em educação para a sexualidade têm menos dificuldade em abordar o tema em sala de aula. A autora ainda ressalta que é necessária uma ação mais efetiva para que a formação de professores em educação para a sexualidade possa ser implementada, pois caso contrário permanecerá de maneira isolada e fragilizada. Corroborando com o insucesso da implementação do tema no contexto escolar.

Temas como sexualidade e o desenvolvimento da educação sexual ainda se apresentam para os docentes como grande desafio e resistência por ser um tema delicado. Além disso, percebe-se que fatores religiosos e culturais têm influenciado no trabalho da educação para a sexualidade pelos docentes. Essa resistência se dá evidentemente pela herança cultural que trata o conhecimento sobre o corpo com fortes preconceitos e tabus, criando dificuldades para a incorporação da temática no debate escolar, como evidencia o depoimento que segue:

"Inibição dos profissionais de educação em abordar o tema por conta de sua postura religiosa e cultural”. (Grupo 3)

Outro problema elencado pelos professores está relacionado a ausência da família frente a educação sexual com os filhos, conforme pode ser confirmado pelas falas dos professores:

"Falta de diálogo da família sobre o tema, os alunos não estão preparados". (Grupo 1)

"Ausência dos pais em reuniões da escola". (Grupo 2)

Considerando a questão relacionada a participação da família frente a educação sexual dos adolescentes, Nery et al. (2015) explicam que os pais têm receio em dialogar com seus filhos sobre sexualidade por medo, vergonha e falta de informações sobre o assunto. Também acreditam que, ao abordar o tema sexualidade, estarão incentivando precocemente seus filhos para a prática sexual. Sobre essa questão, Moreira e Folmer (2015) reiteram que os adultos têm um papel fundamental no acolhimento das dúvidas e curiosidades dos adolescentes, minimizando assim os riscos nesta fase de vulnerabilidade.

Diante desse cenário, na primeira etapa do Arco, é perceptível que os docentes compreendem quais são os problemas relacionados as dificuldades de trabalhar a temática na escola. Assim como, anseiam por um espaço para discussões, reflexões e, sobretudo de estudo. Em que, possibilite maior propriedade técnico - cientifico em relação ao tema e, 
consequentemente autonomia para aborda - lo. Desta forma, possibilitando buscar estratégias para aproximar a escola e a família para um diálogo sobre o tema.

\section{$2^{\text {a }}$ Etapa - Pontos-Chave relacionado ao problema}

Para realização desta etapa, os grupos foram estimulados a refletirem sobre os possíveis fatores que influenciam a existência do problema elencado. Em seguida, os docentes foram convidados a apresentarem em painel aberto os Pontos-chave escolhidos. Durante a apresentação, foram determinados pelos docentes vários Pontos-chave, conforme apresentado no Quadro 1. Então, foi solicitado que definissem apenas dois de maiores prioridades, pois não seria possível trabalhar todos em virtude do tempo. Para com Villardi et al. (2015) nesta etapa são eleitos os pontos considerados prioritários, os quais indicarão caminhos para chegar a uma solução para o problema.

Quadro 1: Pontos-chave apresentados pelos grupos de docentes relacionados aos problemas elencados.

\begin{tabular}{|l|l|}
\hline Grupo de docentes & Pontos-chave \\
\hline Grupo 1 & $\begin{array}{l}\text { • Falta de capacitação dos professores e iniciativa da instituição escolar. } \\
\text { — Tabus religiosos e culturais. }\end{array}$ \\
\hline Grupo 2 & $\begin{array}{l}\text { — Formação continuada para professores específica na área de educação } \\
\text { sexual. }\end{array}$ \\
\hline Grupo 3 & • Integração da família com a escola para conversar sobre sexualidade. \\
\hline Grupo 4 & $\bullet$ Formação continuada para professores em educação sexual. \\
\hline
\end{tabular}

Fonte: Autores da pesquisa, 2019.

Desta maneira, em uniformidade com todos os grupos, a formação continuada para os docentes em educação sexual e a integração da família com a escola foram eleitas como prioridades, entre os Pontos-chave apontados.

\section{$3^{\text {a }}$ Etapa - Teorização para compreensão do problema observado}

Conforme Berbel (1998) a teorização é a etapa que resulta na investigação propriamente dita. Para a autora as informações que buscam estudar sobre o problema elencado, podem ser extraídas por várias fontes como:

Ensino \& Pesquisa, União da Vitória, v. 18, $n^{\circ} 1$, p. 98-120, jan./abr., 2020. 
[...] livros, revistas especializadas, pesquisas já realizadas, jornais, atas de congressos etc.; vão consultar especialistas sobre o assunto; vão observar o fenômeno ocorrendo; aplicam questionários para obter informações de várias ordens (quantitativas ou qualitativas); assistem palestras e aulas quando oportunas etc. (BERBEL,1998, p.143).

Após a escolha dos pontos-chave foi entregue aos professores o artigo "Educação Sexual no contexto familiar, escola: impasses e desafios” dos autores Gonçalves, R.C.; Faleiro, J.H.; Malafaia, G. publicado pela Revista Holos em 2013 para que fizessem a leitura individual e anotações dos pontos que mais chamaram a atenção no referido artigo. Ao término da leitura, foi realizado uma roda de conversa para discussão e a prática reflexiva, gerando o seguinte discurso:

"Filhos são seres assexuados". (P 1)

"O papel da escola em buscar meios de fazer parte da vida do adolescente e negociar diálogos". (P 2)

"A educação sexual é um direito que todas as crianças e adolescentes têm". (P 4)

"A família omissa e a escola despreparada". (P 3)

Diante do exposto, foi possível perceber que a investigação por meio da leitura do artigo contribuiu muito para a construção de novos conhecimentos e Perspectivas sobre a sexualidade. Sobre essa questão, concordamos com Freire (1996) ao inferir que o ensino e a pesquisa devem andar juntos, se almejamos uma educação de qualidade. Também possibilitou que os professores refletissem sobre o seu papel na vida do adolescente e percebê-los como cidadãos de direito, inclusive à informação sobre sexualidade. Para Garnica (2016) o professor, enquanto responsável pela formação do sujeito, precisa estar preparado para as demandas da escola e tornar esse ambiente um espaço de inclusão.

Ao término da roda de conversa, a pesquisadora junto com os professores percebeu que era necessário mais um momento de estudo sobre a temática educação sexual no contexto escolar, antes de seguirem para a próxima etapa. Sendo assim, foi entregue a cada docente uma cópia dos artigos intitulados: "Educação sexual no contexto escolar: as estratégias utilizadas em sala de aula pelos educadores", de autoria de Nogueira, N.S.; Zocca, A.R.; Muzzeti, L.R.; Ribeiro, P.R. publicado pela Revista Holos em 2016 e "Práticas de educação sexual no cotidiano escolar: tecendo reflexões" apresentado no II CONEDU pelos autores Costa, D.M.S.; Moreno, O.S.N.; Miranda, J.R. para serem analisados e discutidos no próximo encontro.

Ensino \& Pesquisa, União da Vitória, v. 18, nº 1, p. 98-120, jan./abr., 2020. 
Com isso, buscou-se superar as limitações quanto ao conceito acerca da sexualidade, possibilitando um maior significado para a importância da educação para a sexualidade no contexto escolar e o papel do professor, fornecendo também subsídios para a elaboração da etapa Hipóteses de Solução.

\section{$4^{\text {a }}$ Etapa - Hipótese de Solução ao problema}

De acordo com Villardi et al. (2015) essa etapa requer criatividade para que as hipóteses de solução do problema sejam elaboradas. As autoras ressaltam que para a formulação das Hipóteses de Solução é preciso levantar algumas questões como: O que é preciso para resolver o problema extraído? Ao iniciar a quarta etapa do Arco de Maguerez, a pesquisadora realizou uma breve apresentação dos resultados de duas perguntas que constaram no questionário que antecedeu o processo do desenvolvimento profissional docente. O objetivo era possibilitar que os grupos retomassem as discussões realizadas nas duas primeiras etapas, e assim auxiliar as reflexões e elaboração das Hipóteses de soluções do problema.

Além das respostas consolidadas, foi apresentado aos professores participantes da formação, duas nuvens de palavras com as facilidades e dificuldades da educação sexual na escola, apontadas pelos referidos professores, conforme figura 1.

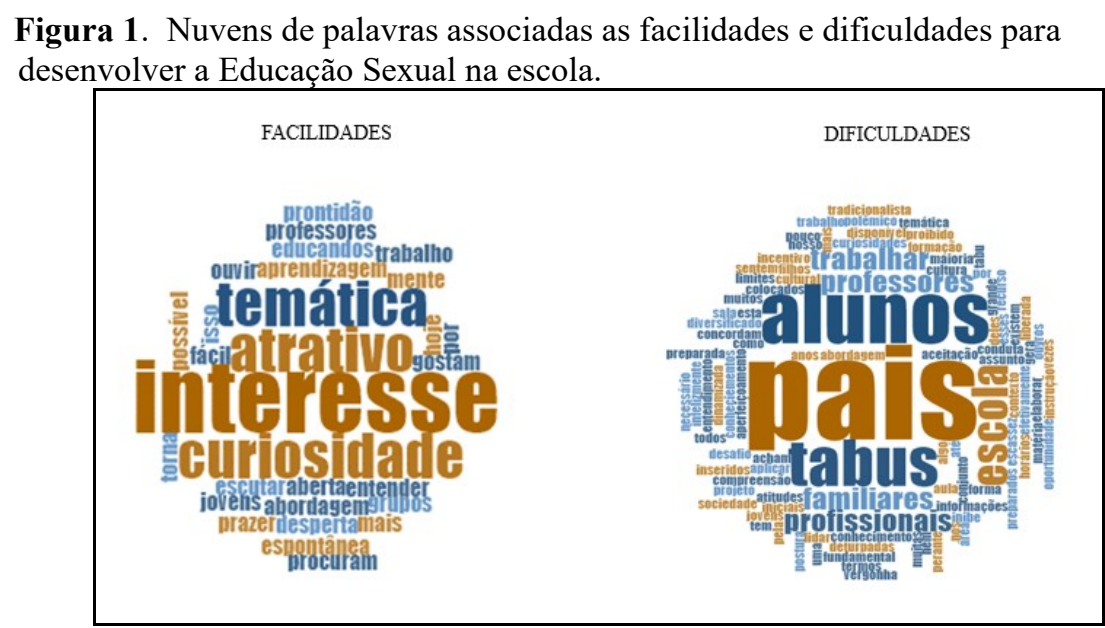

Fonte: Barbosa e Folmer (2019).

Após a apresentação das nuvens de palavras, a pesquisadora encerrou com a seguinte pergunta: Qual a Hipótese de solução que julgam eficiente para a superação do 
problema diagnosticado: Educação Sexual na escola? Em seguida foi entregue a cada grupo cartolina e lápis piloto para que colocassem as hipóteses de solução sugeridas por cada grupo e depois apresentadas como painel aberto para análise e planejamento das ações, conforme figura 2.

Figura 2. Painel aberto com as Hipóteses de Solução

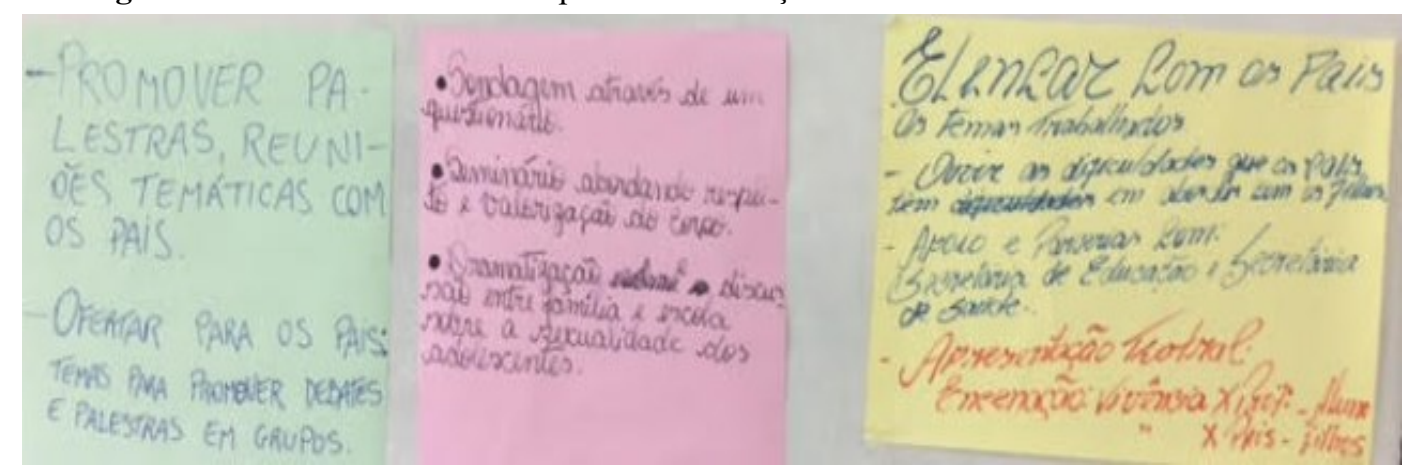

Fonte: Autores da pesquisa, 2019.

As Hipóteses de solução apresentadas pelos grupos de professores foram estruturadas conforme demonstração no quadro 2:

Quadro 2. Hipóteses de solução apresentadas pelos grupos de professores

\begin{tabular}{|l|l|l|}
\hline Hipóteses de solução & Grupo de professores & Atividades sugeridas \\
\hline & Grupo A & $\begin{array}{l}\text { - Promover palestra e reunião temática com os pais. } \\
\text { - Ofertar para os pais temas para promover debates e } \\
\text { palestras em grupos. }\end{array}$ \\
\cline { 2 - 3 } $\begin{array}{l}\text { Encontro família na } \\
\text { escola }\end{array}$ & Grupo B & $\begin{array}{l}\text { - Sondagem através de um questionário para os pais. } \\
\text { - Dramatização e discussão entre família e escola } \\
\text { sobre a sexualidade dos adolescentes. }\end{array}$ \\
\cline { 2 - 3 } & Grupo C & $\begin{array}{l}\text { - Ouvir as dificuldades que os pais têm em abordar o } \\
\text { tema com seus filhos. }\end{array}$ \\
\hline
\end{tabular}

Fonte: Autores da pesquisa, 2019.

Por fim, ficou definido por todos os docentes que seria realizado um encontro dos professores e as famílias denominado "Família na Escola" para o diálogo sobre sexualidade e educação para a sexualidade.

Ensino \& Pesquisa, União da Vitória, v. 18, $n^{\circ} 1$, p. 98-120, jan./abr., 2020. 


\section{$5^{\text {a }}$ Etapa - Aplicação à Realidade}

Para Berbel (1998) a última etapa do arco de Maguerez é caracterizada como a etapa da prática ou momento da ação. Levando em consideração o ponto de partida, ou seja, a realidade social na intenção de transformar essa realidade. Assim, inicialmente os professores indicaram como momento oportuno para aplicação da realidade o evento dia da "Família na escola", que consta no calendário escolar e ocorre semestralmente com o objetivo de reunir os pais para apresentação das notas dos escolares e discutir sobre o comportamento desses.

Os professores da pesquisa sugeriram que fosse planejado um momento para que a escola e a família pudessem dialogar e refletir sobre sexualidade na adolescência e a educação para a sexualidade. Logo, foi aberto espaço para o planejamento das atividades que seriam realizadas. Para a operacionalização desta etapa, foram enviados aos pais e/ou responsáveis uma carta convite emitida pelo gestor da escola.

O evento ocorreu em novembro de 2018 e teve a duração de três horas e meia, com a realização das seguintes atividades: o acolhimento dos familiares e a apresentação das atividades. Em seguida, realizou-se a apresentação de uma peça teatral com uma dramatização sobre sexualidade na adolescência encenada pelos professores. Ao término da dramatização, os familiares foram direcionados para as salas de aulas, de acordo com ano escolar dos respectivos filhos e filhas. Os pais e responsáveis foram acomodados em círculo para facilitar a integração e o diálogo dos familiares e dos professores.

Para dar início a roda de conversa, os professores perguntaram aos familiares se as cenas apresentadas no teatro faziam parte da realidade de cada um em suas casas. Nesse momento foi possível a discussão e reflexão sobre o tema, onde cada pai e mãe pode relatar suas experiências com os filhos e/ou filhas acerca da sexualidade na adolescência. As falas dos pais e mães podem ser observadas no Quadro 3, onde consta as transcrições das informações dos professores por meio de anotações, no qual foram orientados pela pesquisadora durante a fase do planejamento.

Ensino \& Pesquisa, União da Vitória, v. 18, nº 1, p. 98-120, jan./abr., 2020. 
Quadro 3. Desenvolvimento da roda de conversa pais e professores

\begin{tabular}{|c|c|c|c|c|}
\hline Sala & $\begin{array}{l}\text { Ano } \\
\text { escolar }\end{array}$ & $\begin{array}{l}\text { Número de } \\
\text { familiares }\end{array}$ & $\begin{array}{l}\text { Número de } \\
\text { professores }\end{array}$ & Relatos dos pais \\
\hline 01 & $8^{\circ}$ ano & 14 & 06 & $\begin{array}{l}\text { Alguns pais se identificaram com a peça de } \\
\text { teatro. } \\
\text { Outros têm dificuldade de falar com seus filhos } \\
\text { sobre o tema. } \\
\text { Uma mãe disse que não teve orientação dos pais } \\
\text { e engravidou na adolescência. }\end{array}$ \\
\hline 02 & $7^{\circ}$ ano & 11 & 06 & $\begin{array}{l}\text { Os pais relataram que gostaram da peça teatral e } \\
\text { que se identificaram com o tema abordado. } \\
\text { Uma mãe relatou ter dificuldade em conversar } \\
\text { com o assunto sobre sexo, namoro com o filho. } \\
\text { Um pai relatou que pede a esposa que converse } \\
\text { com a filha sobre sexualidade. } \\
\text { Uma mãe disse que falta informação em casa e } \\
\text { que o pai não tem coragem de se abrir com os } \\
\text { filhos para orienta-los. }\end{array}$ \\
\hline 03 & $6^{\circ}$ ano & 14 & 06 & $\begin{array}{l}\text { Um pai relatou que não teve diálogo com seus } \\
\text { pais quando adolescente, aprendeu na escola. } \\
\text { Mas, reconhece a importância de conversar com } \\
\text { seus filhos. }\end{array}$ \\
\hline 04 & $9^{\circ}$ anos & 15 & 06 & $\begin{array}{l}\text { Uma mãe disse que apanhou de corda por } \\
\text { perguntar para a sua mãe o que é sexo. Com isso } \\
\text { ela até hoje tem vergonha de falar sobre } \\
\text { sexualidade. Tem uma filha que engravidou com } \\
13 \text { anos e tem medo que a filha de } 12 \text { anos } \\
\text { também engravide na adolescência. } \\
\text { Um pai relatou que não conversa com seus } \\
\text { filhos porque tem dificuldade, mas acha } \\
\text { importante que a escola aborde assuntos sobre } \\
\text { sexualidade. }\end{array}$ \\
\hline
\end{tabular}

Fonte: Produzido com base nas transcrições dos professores.

Ao finalizar todas as etapas do arco de Maguerez, a pesquisadora teve mais um encontro com os professores para aplicação do questionário e realizar o fechamento do desenvolvimento profissional docente.

\section{Percepções sobre o Arco de Maguerez}

Dos vinte professores que responderam o questionário, dezenove informaram que não conheciam a metodologia da problematização com base no arco de Maguerez. Quanto a percepção acerca da metodologia utilizada, os professores apontaram que é uma metodologia interessante, porquê trabalha a temática a partir do problema e auxilia muito no aprendizado. Como constam nos textos a seguir:

Ensino \& Pesquisa, União da Vitória, v. 18, $n^{\circ} 1$, p. 98-120, jan./abr., 2020. 
"Muito boa porque começa pelo levantamento dos problemas que está acontecendo e procura soluções direcionadas para esses problemas" (P1).

"É de grande relevância, pois nos permite compreender o problema e todas suas particularidades, possibilitando nos chegar a uma solução de problema" (P2).

"Excelente, favorece um trabalho coletivo com planejamento e execução. "Um bom método de aprendizagem" (P 6).

"Foi um método inovador onde acrescentou muito para minha formação e de fato podemos identificar e buscar soluções reais, possíveis" (P13).

Contudo, verificou- se diante das respostas dos professores, que a metodologia da problematização com o arco de Maguerez possibilitou o protagonismo dos professores desde o levantamento dos problemas que acometem a realidade escolar. Assim como, a construção de conhecimentos científicos que favoreceram a elaboração coletiva das soluções. Jardilino e Sampaio (2019) apontam que é fundamental a participação dos professores durante seu processo de desenvolvimento profissional desde o levantamento dos problemas relacionados ao cotidiano do trabalho docente, assim como a busca por soluções.

\section{Potencialidades do Arco de Maguerez}

Foram diversas potencialidades apontadas pelos professores para utilização do arco de Maguerez, pois possibilita enxergar o problema de maneira ampla e crítica, para em seguida buscar soluções de maneira coletiva. As respostas destacadas a seguir colaboram com esse entendimento.

"Visualização ampla do problema para elaboração das soluções" (P 02).

"Através dele podemos alcançar resultados satisfatórios diante da problematização" (P04).

"Entender claramente o passo a passo do problema para a obtenção do resultado" (P 17).

Ainda sobre as potencialidades, os professores elencaram que além de ser um método organizado, as etapas do arco de Maguerez possibilitaram a integração de todos, inclusive dos familiares na escola, conforme as respostas a seguir:

"A integração de todos com diversas opiniões" (P 07).

“A maneira como é realizado por etapas, com a participação de todos” (P 09).

Para Anastácio et al. (2018) o compartilhamento de experiências e a elaboração de soluções para os problemas de maneira coletiva, além de positiva para o desenvolvimento profissional docente, possibilita unificar a prática da educação sexual na escola de maneira 
interdisciplinar. O diálogo entre os professores é fundamental para consolidar saberes emergentes da prática profissional. "Mas, a criação de redes coletivas de trabalho constitui, também, um fator decisivo de socialização profissional e de afirmação de valores próprios da profissão docente" (NÓVOA,1992, p.14).

Logo, compreendemos que o espaço destinado ao desenvolvimento profissional docente, deve favorecer também à partilha de saberes e possibilitar uma construção de novos conhecimentos de forma mútua. Para que esse processo aconteça, Imbernon (2009) afirma que o professor precisa romper com a cultura do isolamento durante sua prática docente. Para o autor, é preciso partir para a coletividade, garantindo a troca de experiências e novos conhecimentos.

\section{Satisfações com o desenvolvimento profissional docente}

Na pergunta sobre a satisfação com o DPD aplicado, constatou-se que todos os professores ficaram satisfeitos. Foram revelados vários motivos que levaram a satisfação. Dentre esses, a possibilidade de terem suas dúvidas acerca temática sexual na escola contemplados. Assim como através dos conhecimentos construídos, os professores se sentiram mais seguros e preparados para abordarem o tema em sala de aula.

"Sim. Pois, através desta formação foi desvendado para nós docentes outro olhar para essa temática, viabilizando essa conversação mais tranquila sobre algo que se fomentava tão obscuro e difícil de lidar" (P 01).

"Sim, porque deu oportunidade de conhecimento em uma área tão pouca explorada" (P 03).

"Sim, pois pudemos tirar dúvidas a respeito do tema" (P11).

"Sim, foi muito importante para nos dar segurança para sabermos como abordar esse assunto em sala de aula" (P15).

\section{Potencialidades do desenvolvimento profissional docente}

Ao serem questionados sobre o desenvolvimento profissional docente, os professores apontaram como potencialidades a oportunidade de construírem conhecimentos acerca do tema trabalhado.

\footnotetext{
"Foi bem diferente, pois nessa formação foi dado subsídios importantes para abordar esta temática em sala" (P 01).

"A segurança para discutir assuntos com diferentes e difíceis temas". (P11)

"Tive uma nova visão sobre educação sexual, com base nos diálogos dos nossos colegas de profissão, da metodologia com base no Arco de Maguerez" (P 14).
}

Ensino \& Pesquisa, União da Vitória, v. 18, $n^{\circ} 1$, p. 98-120, jan./abr., 2020. 
"Mais conhecimentos sobre a forma de abordar o assunto em sala de aula" (P $15)$.

"Conhecimento, quebra de tabu relacionado a abordagem em sala de aula, segurança” (P16).

Com base nas respostas, acreditamos que o método utilizado para o DPD em educação sexual foi fundamental para criar novas possibilidades de discussão sobre a temática. Sobre essa questão, Dias e Ferreira (2018) explicam que é preciso saber escolher bem a ferramenta pedagógica para o desenvolvimento profissional docente, para que não seja apenas mais uma capacitação, e sim uma oportunidade que possibilite reflexões e sobre a prática profissional e traga novos conhecimentos que influencie em mudanças na prática docente.

Sobre os professores terem citado que após o DPD se sentem mais seguros e preparados para tratar o tema em sala de aula, confirma o que Jardilino e Sampaio (2019) defendem ao afirmarem que o DPD deve contribuir para que o professor melhore a qualidade do fazer pedagógico. E também atenda às necessidades da comunidade escolar. Ainda sobre o assunto, Montenegro e Fernandez (2015) destacam que o processo de reflexão sobre a prática docente é fundamental para que o professor possa ressignificar sua prática profissional e assim tornar-se um professor mais autônomo.

Evidenciou-se, ainda, por meio das respostas, que os professores associaram o desenvolvimento profissional docente como um facilitador da integração entre a escola e a família, principalmente para tratar do tema sexualidade. Respeitando a singularidade e as necessidades da escola.

\footnotetext{
"Outra potencialidade foi o encontro com a família, pois percebemos que os pais têm dificuldades e até ignoram muitas questões" (P11).

"Atingiu a meta de envolver a família na escola" (P10).

"Contribuiu de forma positiva para conversar com os pais sobre o tema sexualidade" (P05).

"Excelente, houve interação com a família e escola" (P 08).

"Fortalecimento da família junto à escola, tendo o tema sexualidade como um ponto abrangente para reflexão social entre a escola, o aluno, e a família” (P 20).
}

O espaço familiar e escolar são ambientes privilegiados para o desenvolvimento humano. No entanto, o tema sexualidade ainda é visto por ambos os espaços como polêmico e até tabu. Na perspectiva de Reis e Maia (2012) a aproximação entre escola e família é o primeiro passo para o sucesso da educação para a sexualidade. Logo, reiteramos que é fundamental a implementação de projetos que assegurem a aproximação da família na escola para diálogos e entendimento sobre educação para a sexualidade.

Ensino \& Pesquisa, União da Vitória, v. 18, $n^{\circ} 1$, p. 98-120, jan./abr., 2020. 


\section{Fragilidades do desenvolvimento profissional docente}

Acerca da fragilidade relacionada ao desenvolvimento profissional docente, dos vinte professores que responderam o questionário, seis indicaram que houve pouco tempo.

"Tempo. Em alguns momentos as reuniões poderiam ter tido mais espaço" (P16).

"Pouco tempo para o aprofundamento do tema" (P 11).

"Pouco tempo" (P19).

Entretanto, cabe ressaltar que quando apresentamos a proposta de pesquisa para a coordenação pedagógica, foi determinado pela coordenação os horários em que os professores seriam liberados. Para que não prejudicasse o cumprimento dos conteúdos e dias letivos.

\section{Contribuições do desenvolvimento profissional docente para a prática pedagógica}

Todos os vinte professores que responderam o questionário afirmaram que o desenvolvimento profissional docente contribuirá na sua prática pedagógica. Foram citadas várias contribuições. Os professores apontaram mais segurança na abordagem do tema sexualidade em sala de aula, a partir dos conhecimentos construídos, mudança na condução do tema em virtude da nova percepção sobre educação sexual e sexualidade.

\footnotetext{
"Sim. Muito enriquecedor, pois a partir da mesma trabalharei de forma dinâmica, com mais cuidado e compromisso. Este tema requer muita responsabilidade e conhecimento" (P12).

"Sim. Através dessa formação passei a ter uma nova abordagem para esse tema para com esse tema, pude conhecer a sexualidade e dificuldades dos pais em relação ao tema proposto. Possibilitou um verdadeiro momento de aprendizagem e colaboração" (P13).

"Sim, porque quebrou o tabu sobre esse assunto em sala de aula" (P15)

"Sim, pois na minha disciplina permitirá que aborde temas como educação sexual com maior autonomia no assunto" (P19).
}

As respostas dos professores fortalecem a inferência de que "o desenvolvimento profissional procura promover a mudança junto dos professores, para que estes possam crescer enquanto profissionais e também como pessoas" (MARCELO,2009). Essa mudança foi possível observar na medida em que os professores referiram que suas abordagens em sala de aula serão diferentes. Tratando a temática com mais conhecimento científico ao invés de julgamento, imposição de valores, mitos e tabu.

Ensino \& Pesquisa, União da Vitória, v. 18, nº 1, p. 98-120, jan./abr., 2020. 
Anastácio et al. (2018) assevera que é importante o desenvolvimento profissional docente em educação para sexualidade para "estimular a reflexão e procura de resolução para os problemas com que se deparam os professores no dia-a-dia da escola" (ANASTÁCIO, 2018, p.10). Para Nóvoa (1992) o DPD também deve ser capaz de promover uma ação crítico-reflexiva, favorecendo o desenvolvimento de uma prática docente com mais autonomia. Para isso, "a formação docente não pode estar alicerçada em cursos que não estabelecem relação com o cotidiano, com as práticas profissionais e com as demandas de formação trazidas pelos professores" (JARDILINO E SAMPAIO, 2019, p.185).

\section{Considerações finais}

Ao trabalhar com a referida metodologia, foi possível romper com a formação continuada tradicional, em que os professores são apenas ouvintes. Nesse modelo, os professores foram estimulados desde o início a buscarem pela construção de novos conhecimentos acerca da temática educação para a sexualidade. O que possibilita uma maior autonomia e conforto na abordagem do tema em sala de aula. Pois, em todo processo, os professores elencavam que não se sentiam preparados para abordar o tema juntos aos seus escolares.

Os professores apontam a metodologia como interessante e eficaz para trabalhar temas polêmicos, como a sexualidade. Tendo em vista que a mesma permite iniciar com o levantamento do problema e a construção coletiva das soluções. Diante do exposto, fica a proposta de utilizar a MP com o arco de Maguerez como estratégia para o desenvolvimento profissional docente em educação para a sexualidade, uma vez que por meio dessa metodologia, os professores envolvidos foram protagonistas durante todo processo.

Contatou-se que por meio dos estudos e discussões sobre a educação para sexualidade os professores apontaram que, a partir de agora terão um novo olhar para as questões que envolvem a sexualidade. Os mesmos estão dispostos a modificarem seus conceitos e prática docente em relação a temática, rompendo com mitos e tabus.

Podemos afirmar que por meio da MP com o arco de Maguerez foi possível aproximar a família e a escola para o diálogo e reflexão sobre a importância da educação para a sexualidade em ambos os contextos. Fator que era considerado pelos professores

Ensino \& Pesquisa, União da Vitória, v. 18, $n^{\circ} 1$, p. 98-120, jan./abr., 2020. 
como importante e necessário para a implementação da abordagem sobre sexualidade na sala de aula.

Por fim, acreditamos que a utilização da MP com o arco de Maguerez foi positiva e possibilitou muitas contribuições para a ressignificação da prática docente dos professores envolvidos. Desta maneira, espera-se que com a realização do desenvolvimento profissional docente seja possível superar os desafios que impedem a implementação da educação em sexualidade no contexto escolar.

No entanto, compreendemos que a mudança na prática docente pode ser de médio a longo prazo, pois o desenvolvimento profissional docente é um processo contínuo. Portanto, sugere-se que a MP com o arco de Maguerez para o desenvolvimento profissional docente em educação para a sexualidade seja incorporado aos programas de formação pedagógica. Por tratar - se de um tema pertinente, espera-se que novas pesquisas sejam realizadas, principalmente envolvendo os adultos de referência (pais, professores e profissionais de saúde).

\section{Referências}

ANASTÁCIO, Z. Os professores e a Educação sexual no Ensino Básico: necessidades de formação e sua importância na evolução conceptual. In D. Freitas, G. Dutra de Carvalho, M. Fávero, P. Costa; V. Marques Santos (Orgs). Projeto Web Educação Sexual: a educação no espaço escolar, 2018, p. 93-108. Florianópolis: UDESC. (ISBN: 978-85-8302-151-3).

BARBOSA, L. U.; VIÇOSA, C. S. C. L.; FOLMER, V. A educação sexual nos documentos das políticas de educação e suas ressignificações. Revista Eletrônica Acervo Saúde, v. 11, n. 10, p. e772, 8 jul. 2019. Disponível em: https://acervomais. com.br/index.php/saude/article/ view/772. Acesso em: 10 jul.2019.

BERBEL, N.A.A. A Problematização e a Aprendizagem Baseada em Problemas: diferentes termos ou diferentes caminhos? Interface-Comunicação, Saúde, Educação, v.2.n.2,1998.

CARMAN, M., MITCHELL, A., SCHLICHTHORST, M. SMITH, A. Teacher training in sexuality education in Australia: how well are teachers prepared for the job? Sexual Health, v. 8, p. 269-271, 2011. Disponível em: www.publish.csiro. au/ journals/sh. Acesso em: 21 ago 2019.

Ensino \& Pesquisa, União da Vitória, v. 18, nº 1, p. 98-120, jan./abr., 2020. 
DIAS, L. F.; FERREIRA, M. POLÍTICAS DE FORMAÇÃO CONTINUADA DE PROFESSORES E DESENVOLVIMENTO PROFISSIONAL. REVISTA PESQUISA E DEBATE EM EDUCAÇÃO. V.7, N. 2, P.391-411, 2017. DISPONÍVEL EM: HTTP://WWW. REVISTAPPGP .CAEDUFJF.NET/INDEX. PHP/REVISTA 1/ARTICLE/ VIEW/206/132. ACESSO EM: 21 OUT.2019.

ESPERIDIÃO, E.; SOUZA, A.C.S.; CAIXETA, C.C.; PINHO, E.S.; NUNES, F. C. Arco de Maguerez: estratégia de metodologia ativa para coleta de dados. $6^{\circ}$ Congresso IberoAmericano em Investigação Qualitativa (CIAIQ2017). Disponível em: https:// proceedings. ciaiq.org/ index.php/ciaiq2017/article/view/127.

FREIRE, P. Pedagogia da Autonomia: saberes necessários à prática educativa. São Paulo: Paz e Terra, 1996. (Coleção Leitura).

FURLANETTO, M. F.; LAUERMANN, F.; COSTA, C.B. da; MARINI, A. H. Educação sexual em escolas brasileiras: revisão sistemática da literatura. Cadernos de Pesquisa, v. 48, n. 168 (Abr. - jun.), p. 550-571, 2018, D6502674.em: https:// dialnet.unirioja. es/servlet/ articulo? codigo $=6502674$. Acesso em: 2 nov. 2018.

GARNICA, T. P. B. et al. O Saber-fazer na Formação de Professores para a Inclusão Escolar: um Levantamento Bibliográfico. Ensino \& Pesquisa, [S.1.], nov. 2016. ISSN 2359-4381. Disponível em: <http://periodicos.unespar.edu.br/index.php Lensinoepesquisa/ article/view/970/599>. Acesso em: 21 nov.2019.

GONÇALVES, R. C.; PAES, D. C.; FAVORITO, A.P. Educação sexual nas séries iniciais do ensino fundamental: o que educadoras da rede municipal de ensino de Pires do Rio (Goiás) têm a dizer? Multi-Science Journal, v.1, n.3, p.69-78, 2015. Disponível em: https://www. ifgoiano.edu.br/periodicos/index.php/multiscience/ article/view/122. Acesso em: 21 out. 2019.

IMBERNÓN, F. Formação continuada de professores- Porto Alegre: Artmed, 2010.

IMBERNÓN, F. Formação permanente do professorado: novas tendências. São Paulo, Brasil: Cortez, 2009.

JARDILINO, J. R.; SAMPAIO, A. M. Desenvolvimento profissional docente: Reflexões sobre política pública de formação de professores. Educação \& Formação, v. 4, n. 10 jan/abr, p. 180-194, 9 jan. 2019. Disponível em: https://revistas.uece.br/index. php/redufor /article/view/848. Acesso em 19 nov.2019.

LACERDA.V. L.; MELO. G. F. Formação e desenvolvimento profissional de professoras da Educação Básica. Ensino Em Re-Vista, v. 24, n. 02, p.431-450. 2017. Disponível em: http://www.seer.ufu.br/index.php/emrevista/about. Acesso em: 21 out. 2019.

MARCELO, C. Desenvolvimento Profissional Docente: passado e futuro. Revista de Ciências da Educação, n.8, p. 7-22, jan- abr, 2009. Disponível em: http://www.unitau. br/files/arquivos/category 1/MARCELO Desenvolvimento Profissional Docente passado_e futuro_1386180263.pdf. Acesso em: 30 jul.2019.

Ensino \& Pesquisa, União da Vitória, v. 18, $n^{\circ} 1$, p. 98-120, jan./abr., 2020. 
MOREIRA, B. R.; FOLMER, V. Percepções de professores de ciências e educação física acerca da educação sexual na escola. Revista Experiência em Ensino de Ciências, v.10, n.3, p.18-20, 2015.

Montenegro, v. L. S. dos; FERnANDEZ, Carmen. Processo reflexivo e desenvolvimento do conhecimento pedagógico do conteúdo numa intervenção formativa com professores de química. Revista Ensaio Pesquisa Educação em Ciências. v. 17 n. 1 p. 251-275 jan-abr 2015. Disponível em: https://periodicos .ufmg. br/index. php/ensaio/ article/view /10117. Acesso em: 21 out. 2019.

NERY, I. S.; FEITOSA, J. J. M.; SOUSA, A. F.L.; FERNANDES, A. C. N. Abordagem da sexualidade no diálogo entre pais e adolescentes. Acta Paul Enferm, v. 28, n.3, p.28792,2015. Disponível em: http://www.scielo.br/pdf/ape/v28n3/1982-0194-ape-28-030287.pdf. Acesso em:30 jul.2019.

NÓVOA, A. Formação de professores e profissão docente. 1992. Disponível em: https://core.ac.uk/download/pdf/12424596.pdf. Acesso em: 06 out. 2019.

PERES, C., LARA, S., COPETTI, J., LANES, K., \& SOARES, M. Percepção de estudantes sobre saúde, alimentação e atividade física após intervenção com a metodologia da problematização. Revista Contexto \& Educação, v.33, n.104, 346-364, 2018.https://doi. org/10.21527/2179-1309.2018.104.346-364. Acesso em: 30 jul. 2019.

POUND P, L. R, Campbell R. What do young people think about their school-based sex and relationship education? A qualitative synthesis of young people's views and experiences.BMJ Open 2016;6:e011329. doi: 10.1136/bmjopen-2016-011329.

PORTUGAL. Diário da República, 1. a série - n. 151 - 06 ago. 2009. Disponível em: http://dre.pt/pdf1s/2009/08/15100/0509705098.pdf. Acesso em: 19 ago.2019.

REIS, V. L. MAIA, A. C. B. Educação sexual na escola com a participação da família e o uso de novas tecnologias da educação: um levantamento bibliográfico. Cadernos de Educação, Pelotas, v. 4, p. 188-207, 2012. Disponível em: http: //periodicos.ufpel. edu. br/ojs2/index .php/caduc/article/viewFile/2099/1937. Acesso em: 10 out. 2019.

SANTOS, D.C. M. A Importância das Questões de Gênero e Sexualidade na Formação Docente. Coisas do Gênero, v.4, n.1, p.102 - 115, 2018. Disponível em: http://periodicos. est.edu.br/index.php/genero. Acesso em: 30 jul. 2019.

SANTOS, C. F. dos; SANTOS, R. M. R. dos. Desafios na formação docente em diversidade sexual. Educação: Teoria e Prática, v. 29, n.60, p. 140-161, 2019. Disponível em: https://doi.org/10.18675/1981-8106.vol29.n60.p140-161. Acesso em: 21 out.2019.

SILVA, F. S. da; NOBRE, S. B. A educação sexual na formação inicial docente. XXIX SALÃO DE INICIAÇÃOCIENTÍFICA DA UFRGS,2017. 
TORRES, Juliana Rezende et al. Sexualidade e gênero na escola: construindo atividades formativas na rede pública de ensino através do PIBID. Ensino \& Pesquisa, [S.1.], mar. 2016. ISSN 2359-4381. Disponível em: < $\underline{\text { http://periodicos. unespar.edu.br/index. php/ }}$ ensinoepesquisa/article/view/638/498>. Acesso em: 19 nov. 2019.

VILLARDI, M.L.; CYRINO, E.G.; BERBEL, N.AN.A metodologia da problematização no ensino em saúde: suas etapas e possibilidades. In: A problematização em educação em saúde: percepções dos professores tutores e alunos [online]. São Paulo: Editora UNESP; São Paulo: Cultura Acadêmica, 2015, pp. 45-52.ISBN 978-85-7983-662-6. Available from SciELO Books. Disponível em: http://books.scielo.org/id/dgjm7/pdf/villardi9788579836626-05.pdf. Acesso em: 21 out.2019. 